Case Report

\title{
Premaxillary and maxillary sinus mucormycosis post COVID: a rare case report
}

\author{
Deependra Shrestha, Reskey Dev*
}

Department of ENT and Head and Neck Surgery, Norvic International Hospital, Kathmandu, Nepal

Received: 28 September 2021

Revised: 02 November 2021

Accepted: 03 November 2021

\author{
*Correspondence: \\ Dr. Reskey Dev, \\ E-mail: reskeydev@gmail.com
}

Copyright: (c) the author(s), publisher and licensee Medip Academy. This is an open-access article distributed under the terms of the Creative Commons Attribution Non-Commercial License, which permits unrestricted non-commercial use, distribution, and reproduction in any medium, provided the original work is properly cited.

\begin{abstract}
Mucormycosis, previously termed as zygomycosis, is an opportunistic infection and is caused by fungi belonging to the order Mucorales. It is found in patients with predisposing conditions such as diabetic ketoacidosis, chronic kidney disease malignancy long-term steroid use and immunosuppressant drugs. Mucormycosis involving paranasal sinuses is a rare life-threatening opportunistic infection in a covid positive patient. The unprescribed use of corticosteroid in covid positive patient, the lymphopenia in severe covid 19 cases, preexisting diseases like uncontrolled diabetes mellitus, hematological malignancy, stem cell transplant causing weak immune system are the factors which are responsible for mucor infection in covid positive patients. We herein report the case of maxillary and premaxillary mucormycosis infection in the uncontrolled diabetic patient with post covid status in recovering phase of acute respiratory distress syndrome.
\end{abstract}

Keywords: Mucormycosis, COVID-19, Sinonasal disease

\section{INTRODUCTION}

The pandemic of coronavirus disease 2019 (COVID-19) which is caused by the severe acute respiratory syndrome coronavirus 2 (SARS-CoV-2) has resulted in huge number of morbidity and mortality. ${ }^{1}$ The situation in developing countries like Nepal and India which have been facing the second wave of COVID-19 due to a new mutated variant of SARS-CoV-2 known as B.1.617 is really frightening. ${ }^{2}$ The virus has not only affected the huge population in Nepal and India directly but it has also resulted in the sudden development of rare opportunistic infections like Mucormycosis. ${ }^{3}$ Mucormycosis is a rare devastating acute invasive filamentous fungal infection caused by inhalation of spores of ubiquitous fungi belonging to order Mucorales of family Mucoraceae. ${ }^{4}$ Mucormycosis is considered as one of the most rapidly progressive lethal forms of fungal infection with a high mortality rate of $70-100 \%$.The disease becomes evident in individuals with a weak immune system either due to any preexisting disease like uncontrolled diabetes mellitus (DM), hematological malignancy, and patients on systemic corticosteroid use, prolonged neutropenia, or stem cell transplant. ${ }^{5}$ The lasting lymphopenia in severe COVID-19 cases could be an essential contributor to the vulnerability of these patients to mucormycosis. Drugs like corticosteroids for example methylprednisolone and dexamethasone are mainly used in the treatment of COVID-19. Their side effects include increased secondary infections, immune modulation, manifestation of latent diabetes mellitus, dizziness, weight gain, mood changes, insomnia and muscle weakness. ${ }^{6}$ Unprescribed use of these drugs are also one of the reason of increased number of mucormycosis patient in COVID-19 patient. Mucormycosis is difficult to diagnosis, which affects outcome and results in poor prognosis. Early diagnosis and treatment are essential. Delay of a week often 
doubles the 30-day mortality from $35 \%$ to $66 \%$. Despite early aggressive combined surgical and medical therapy, the prognosis of mucormycosis is poor. ${ }^{7}$

\section{CASE REPORT}

The 56-year-old female known case of covid positive admitted to the hospital for decrease in $\mathrm{SpO}_{2}$ and breathing difficulty. She was admitted in MICU and was on CPAP and high flow nasal cannula and face mask on and off for 25 days. On $25^{\text {th }}$ day, she started having left side of facial swelling and red eye left side. She was on facemask that time maintaining spo $289-90 \%$ at $8 \mathrm{~L}$ of oxygen. There was no any nasal discharge, nasal blockage. Patient were known case of DM for 10 years but she was taking the medicine irregularly.

On examination anterior rhinoscopy and rigid endoscopy was normal. There was mild congestion of mucosa, no any discharge, and no any black coloured turbinate. Throat examination was normal. No any black coloured area seen in palate or gum. Anteriorly skin over left cheek were swollen with redness. Tenderness was present. Left eye was congested (Figure 1). In ophthalmologic examination, her vision was normal.

Keeping mucormycosis as first diagnosis contrast, enhanced MRI were done and along with-it nasal swab was taken for $\mathrm{KOH}$ mount. $\mathrm{KOH}$ mount was negative. Her MRI report says mucosal thickening involving all the sinuses with few low signal foci/regions in the left maxillary sinus on T2W. Fluid levels in the left maxillary and right sphenoid sinuses. Debris in the right maxillary sinus. Increased signal on T2W/FLAIR as well as mild enlargement of the inferior oblique and inferior rectus muscles of left orbit suggestive of edema/inflammation with associated mild left proptosis. Increased signal on T2W/FLAIR involving the left peri orbital region, left nose, left temporal fossa, left anterior masticator space, left periantral fat and subcutaneous tissue and muscles of the left face/cheek suggestive of edema/inflammation. There is non-enhancement of the premaxillary region soft tissue measuring approximately $3.4 \times 1.1 \times 2.4 \mathrm{~cm}$ $(\mathrm{CC} \times \mathrm{AP} \times \mathrm{TR})$ likely representing necrosis with abscess as differential consideration. Left osteomeatal complex appears obliterated. Findings are concerning for fungal infection (Mucormycosis) as described above (Figure 2 and 3).

Amphotericin B was started immediately. FESS was planned along with Caldwell Luc's operation to address the cheek area and infratemporal area. On endoscopic examination nose looked normal with no any secretion or blackish area (Figure 4). Uncinectomy was done and maxillary sinus opening was enlarged. Fungal debris could be seen in maxillary sinus opening (Figure 5). After this sub labial incision was given and periosteum elevated over maxillary sinus. Bone over maxillary sinus was blackish in colour and friable anteriorly (Figure 6). After the anterior bone was removed blackish mass was present in the sinus which was removed (Figure 7). Maxillary sinus was cleared. Its floor and posterior wall was intact. Medially wall was drilled and removed. Superiorly bone was necrosed and blackish debris were seen below orbit. This debris was removed from the inferior rectus muscle till bleeding was seen. Laterally bone was drilled and fungal debris removed. There was necrosed area in the cheek with $2 \mathrm{ml}$ of pus which was removed in total (Figure 8). After this nose and maxillary sinus was packed with amphotericin B pack and sub labial area sutured. The biopsy (Figure 9) was sent for $\mathrm{KOH}$ mount and histopathology. The pack was removed on $2^{\text {nd }}$ day. Injection amphotericin B was continued till 10 days after which oral Posaconazole was started. Histopathology report microscopic feature says that there are numerous non septate to minimally septated broad, ribbon like hyphae few showing branching angle and septation structure. Specimen stain PAS positive. Overall features are compatible with fungal infection morphologically consistent with mucormycosis.

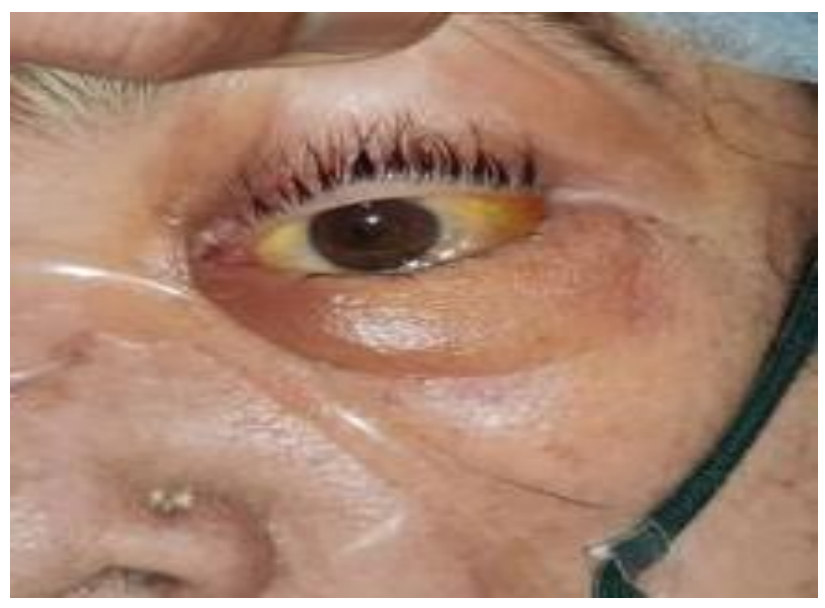

Figure 1: Eye congestion.

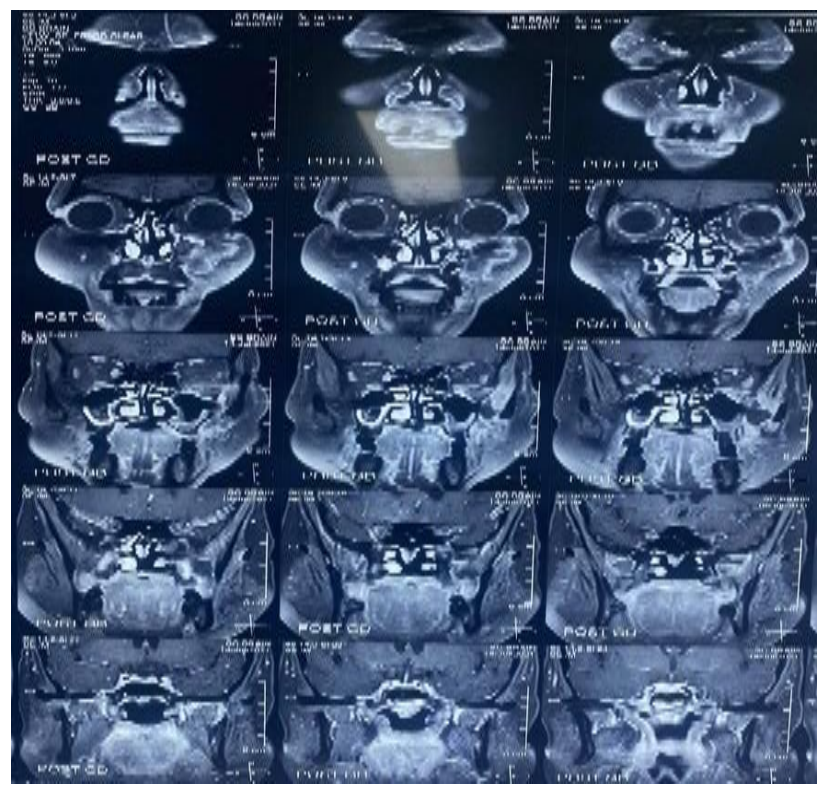

Figure 2: MRI coronal section. 


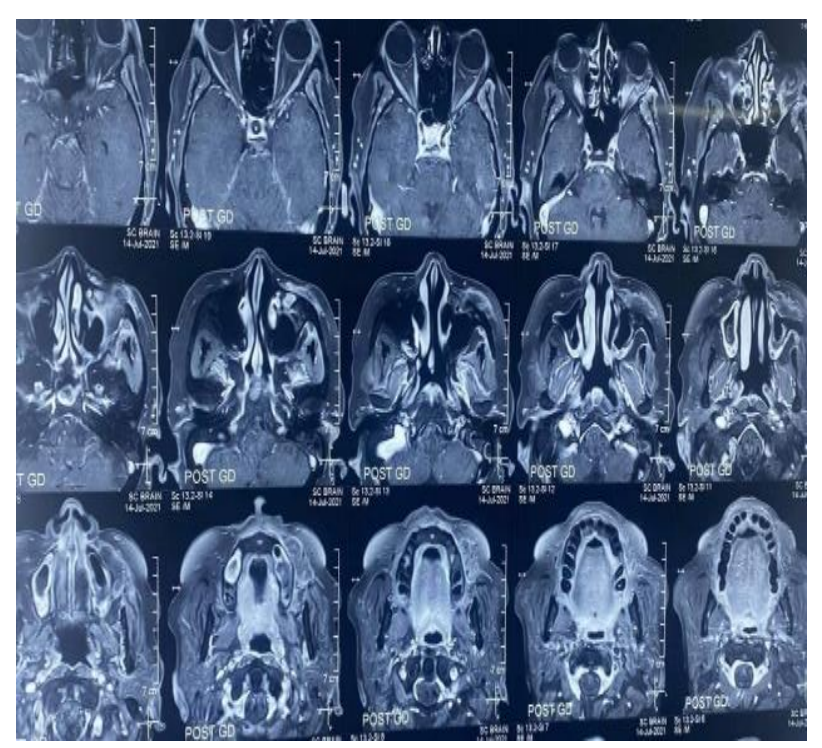

Figure 3: MRI axial cuts.

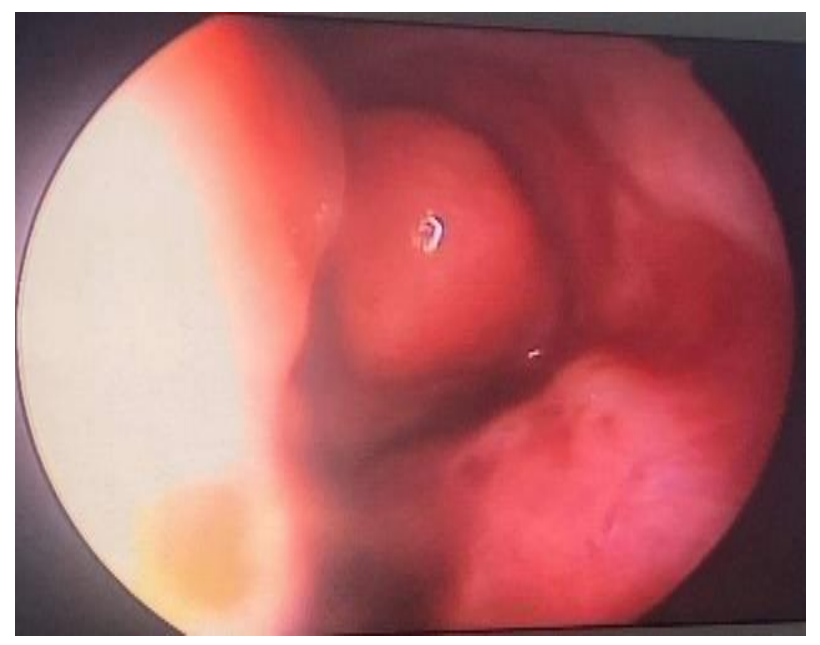

Figure 4: Normal nasal endoscopy.

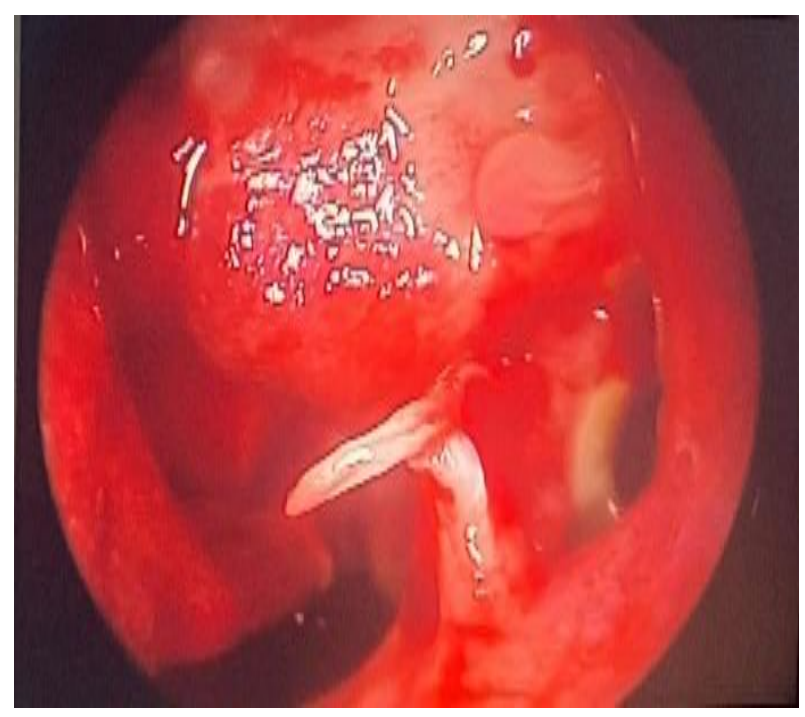

Figure 5: Middle meatal antrostomy with pus visualized in maxillary antrum.

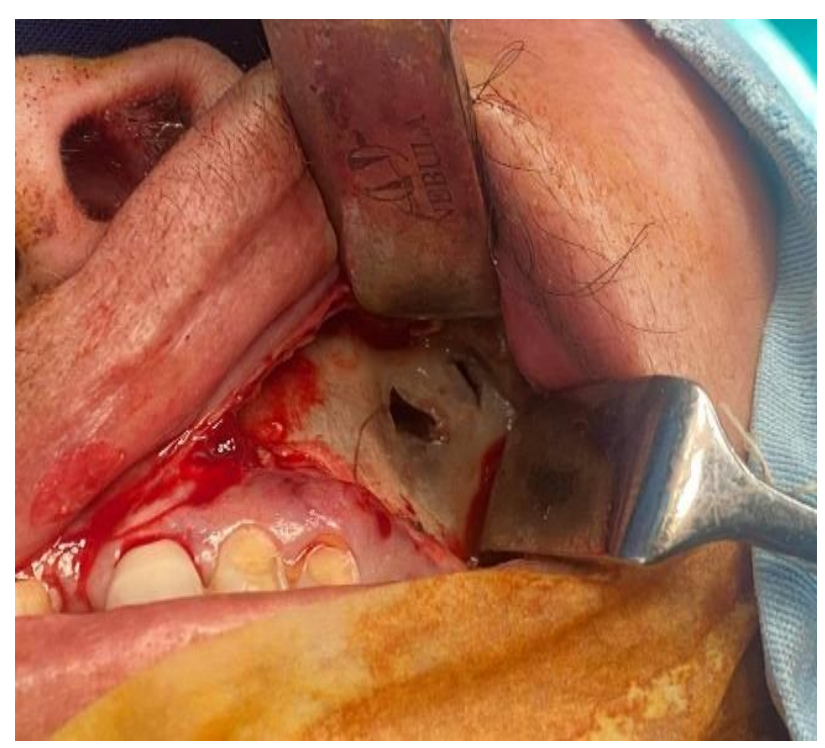

Figure 6: Anterior wall of maxilla.

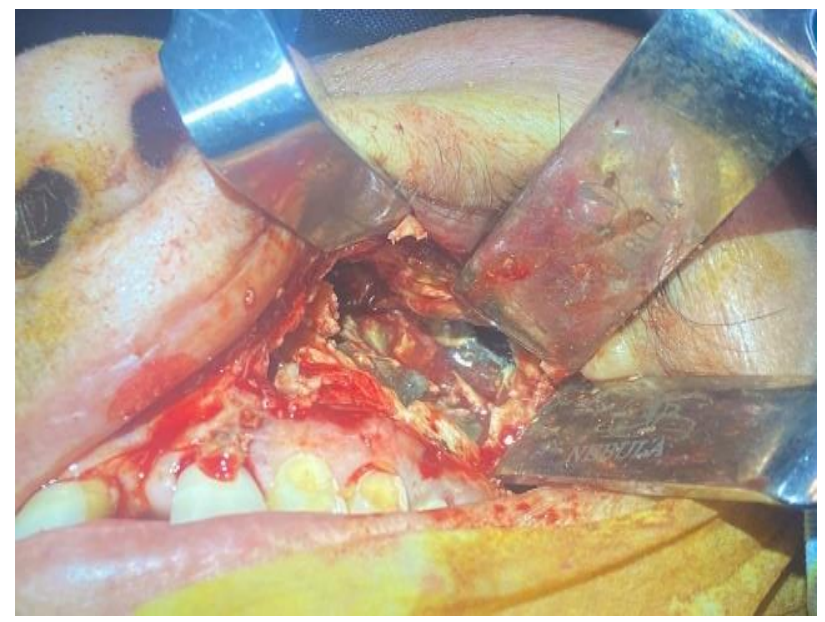

Figure 7: Debris in maxillary antrum.

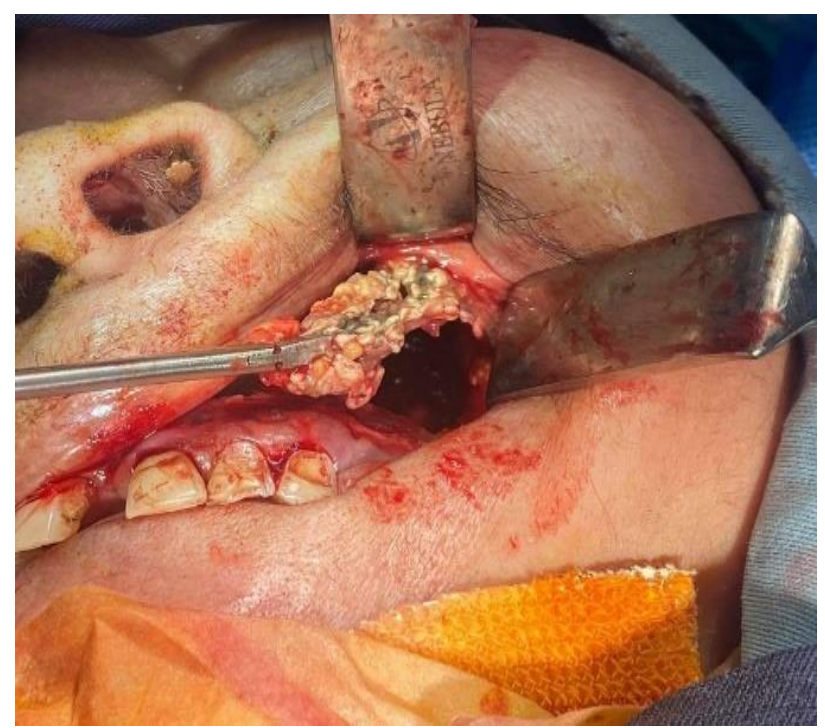

Figure 8: Debris in premaxillary area. 


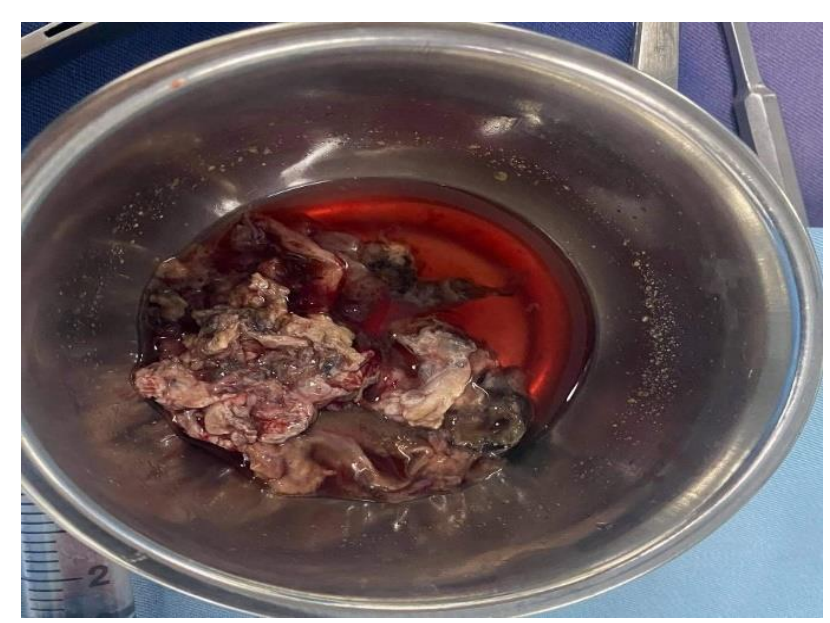

Figure 9: Fungal debris after surgery.

\section{DISCUSSION}

A myriad of co-infections of viral, fungal, and bacterial etiology and associated complications have been encountered in patients of COVID-19.,8 During the current second wave in Nepal the fungal infection has dominated other infections. There are specific pathophysiologic features of COVID-19 that may permit secondary fungal infections, including a propensity to cause extensive pulmonary disease and the subsequent alveolo-interstitial pathology that may enhance the risk of invasive fungal infections. Second, the immune dysregulation associated with COVID-19, with reduced numbers of $\mathrm{T}$ lymphocytes, CD4+T, and CD8+T cells, may alter innate immunity. ${ }^{9}$ Pathogenic mechanisms involved in fungal aggressiveness include decreased phagocytic activity, accessible amounts of iron due to the displacement of protons by transferrin in diabetic ketoacidosis and fungal heme oxygenase, which promotes iron absorption for its metabolism. Corticosteroid therapy and a past history of chronic pulmonary disease were associated with a higher risk of invasive fungal disease. ${ }^{10}$ Also, there are certain other factors that could be detrimental to the mucormycosis infection like excessive use of zinc, iron, and aluminium leading to an overload of these minerals thus contributing to the growth of mucormycosis. ${ }^{11,12}$ Other potential contributors could be widespread and over the counter use of antibiotics (like doxycycline, azithromycin, ivermectin, etc.); immunomodulators (like toculizumab with steroids); immune suppression by the B1.617 variant of COVID-19 virus; reuse of mask and cannulas; industrial oxygen use instead of medical oxygen in patients; use of tap water instead of distilled water in humidifiers; lack of hygiene in overwhelmed hospitals; use of unhygienic masks, ventilators, oxygen systems, humidifiers etc. ${ }^{13}$

Mucoraceae are ubiquitous saprophytic fungi and are common inhabitants of decaying matter also found in bread, soil, air, dust and hospital ward rooms. ${ }^{14-16}$ The organisms are potent in the temperate climates. ${ }^{17}$ The mold usually gains entry into the host through the respiratory tract and exhibits a remarkable affinity for arteries and grows along internal elastic lamina causing thrombosis and infarction. ${ }^{18,19}$ The progression of the disease from nose and sinuses is either direct or through vascular occlusion. Intracranial involvement also occurs by invasion through superior orbital fissure, ophthalmic vessels, cribriform plate, carotid artery or possibly via a perineural route. ${ }^{20,21}$

Diagnosis is classically dependent on clinical features, pathological findings and imaging plays an important role in defining the extent of involvement. ${ }^{22} \mathrm{MRI}$ is a valuable modality that can be used to diagnose mucormycosis infections involving sino-nasal region, orbits, and possible intracranial extension. ${ }^{23}$ The multiplanar capabilities of MRI with its superior soft tissue depiction are helpful in delineating the anatomical extent of disease as well as its complications. ${ }^{23,24}$ Early establishment of the diagnosis and prompt surgical intervention aids in controlling the extent and severity of the disease.

The primary guideline for treating the disease is to correct the underlying cause, but this cannot be achieved in patients dependent on high dose steroid therapy like in COVID-19. A coordinated effort from a multidisciplinary team including ophthalmology, otorhinolaryngology, infectious diseases, neurosurgery, critical care, microbiology and pathology department is crucial. The two mainstays of treatment are medical treatment with amphotericin B and surgical debridement. Amphotericin $\mathrm{B}$ is a fungistatic agent rather than fungicidal, which leads to longer treatment duration. Prognosis is dependent on multiple factors and early initiation of treatment is an important element. A delay of even 6 days in initiating treatment doubles the 30-day mortality from $35 \%$ to $66 \%$.

So, a high index of suspicion with judicious use of diagnostics, medicines, and surgeries could well be an answer to the growing problem of mucormycosis in the COVID-19 pandemic.

\section{CONCLUSION}

COVID-19 is associated with a significant incidence of secondary infections, mostly fungal probably due to immune dysregulation. Additionally, the widespread use of steroids/monoclonal antibodies/broad-spectrum antibiotics as part of the treatment against COVID-19 may lead to the development/exacerbation of preexisting fungal diseases. Here in we present a case of mucormycosis in maxillary and premaxillary area of post covid patient who was in the treatment of acute respiratory distress syndrome. She was in oxygen $8 \mathrm{~L}$ using face mask. After surgery her condition improved.

Funding: No funding sources

Conflict of interest: None declared

Ethical approval: Not required 


\section{REFERENCES}

1. UNCTAD. Impact of the COVID-19 pandemic on trade and development: transitioning to a new normal. Available at: https://unctad.org/webflyer/ impact-covid-19-pandemic-trade-and-developmenttransitioning-new-normal. Accessed on 10 Jan, 2021.

2. Agarwal SL. What We Know about India's Covid-19 Variant B.1.617. Available at: https://www.wsj.com/ articles/what-we-know-about-indias-double-mutantcovid-19-variant-11619193481. Accessed on 10 Jan, 2021.

3. Biswas S. Mucormycosis: The 'black fungus' maiming Covid patients in India. Available at: https://www.bbc.com/news/world-asia-india57027829. Accessed on 10 Jan, 2021.

4. CDC. Where Mucormycosis comes from. Available at: https://www.cdc.gov/fungal/diseases/ mucormycosis/causes.html\#: :text=Mucormycetes $\%$ 2C\%20the $\% 20$ group $\% 20$ of $\% 20$ fungi, than $\% 20$ in $\% 20$ winter\%20or\%20spring. Accessed on 10 Jan, 2021.

5. Mekonnen ZK, Ashraf DC, Jankowski T, Grob SR, Vagefi MR, Kersten RC. Acute Invasive RhinoOrbital Mucormycosis in a Patient with COVID-19Associated Acute Respiratory Distress Syndrome Ophthalmic. Plast Reconstr Surg. 2021;37(2):e40-80.

6. Methylprednisolone for patients with COVID-19 severe acute respiratory syndrome-full text view ClinicalTrials.gov. Available at: https://clinicaltrials.gov/ct2/show/NCT04323592. Accessed on 10 Jan, 2021.

7. Werthman-Ehrenreich A. Mucormycosis with orbital compartment syndrome in a patient with COVID-19. Am J Emerg Med. 2021;42:264.e5-264.e8.

8. Chen X, Liao B, Cheng L, Peng X, Xu X, Li Y, et al. The microbial coinfection in COVID-19. Appl Microbiol Biotechnol. 2020;104(18):7777-85.

9. Gangneux JP, Bougnoux ME, Dannaoui E, Cornet $\mathrm{M}$, Zahar JR. Invasive fungal diseases during COVID-19: we should be prepared. J Mycol Med. 2020;30:100971.

10. White PL, Dhillon R, Cordey A. A national strategy to diagnose COVID-19 associated invasive fungal disease in the ICU.Clin Infect Dis. 2020;73(7):e1634-44.

11. Iyer M. Zinc overuse driving black fungus epidemic within pandemic? Doctors want study. Available at: https://timesofindia.indiatimes.com/city/mumbai/mu mbai-zinc-overuse-driving-mucor-epidemic-withinpandemic-docs-want-study/articleshow/82922957. cms. Accessed on 10 Jan, 2021.

12. McNab AA, McKelvie P. Iron Overload Is a Risk Factor for Zygomycosis Arch Ophthalmol. 1997;115(7):919-21.
13. Black fungus, white fungus, yellow fungus: What we know about post-Covid infections. Available at: https://www.hindustantimes.com/india-news/blackfungus-white-fungus-yellow-fungus-what-we-knowabout-post-covid-infections-101622102847311.html. Accessed on 10 Jan, 2021.

14. Safi M, Ang MJ, Patel P. Silkiss Rhino-orbitalcerebral mucormycosis (ROCM) and associated cerebritis treated with adjuvant retrobulbar amphotericin B. Am J Ophthalmol Case Rep. 2020;19:100771.

15. Kolekar JS. Rhinocerebral mucormycosis: a retrospective study Indian J. Otolaryngol. Head Neck Surg. 2015;67(1);93-6.

16. Camara-Lemarroy CR, González-Moreno R, Rodríguez-Gutiérrez EJ, Rendón-Ramírez AS, Ayala-Cortés ML, Fraga-Hernández L et al. Clinical features and outcome of mucormycosis Interdiscip. Perspect Infect Dis. 2014;562610.

17. Talmi YP, Goldschmied-Reouven M, Bakon I, Barshack M, Wolf Z, Horowitz A et al. Rhino-orbital and rhino-orbito-cerebral mucormycosis Otolaryngol. Head Neck Surg. 2002;127(1):22-31.

18. Gupta SR, Goyal NM, Kaore M. Rhino-orbitalcerebral mucormycosis: battle with the deadly enemy Indian J. Otolaryngol. Head Neck Surg. 2020;72(1):104-11.

19. Groote CA. Rhinocerebral phycomycosis. Arch Otolaryngol. 1970;92(3):288-92.

20. Bawankar P, Lahane S, Pathak P, Gonde P, Singh A. Central retinal artery occlusion as the presenting manifestation of invasive rhino-orbital-cerebral mucormycosis Taiwan

Ophthalmol. 2020;10(1):62-5.

21. Parsi K, Itgampalli RK, Vittal R, Kumar A. Perineural spread of rhino-orbitocerebral mucormycosis caused by Apophysomyces elegans Ann. Indian Acad. Neurol. 2013;16(3):414.

22. Deutsch PG, Whittaker J, Prasad S. Invasive and non-invasive fungal rhinosinusitis-a review and update of the evidence. Medicina. 2019;55:1-14.

23. Herrera DA, Dublin AB, Ormsby EL, Aminpour S, Howell LP. Imaging findings of rhinocerebral mucormycosis. Skull base. 2019;19(2):117-25.

Therakathu J, Prabhu S, Irodi A, Sudhakar SV, Yadav VK, Rupa V. Imaging features of rhinocerebral mucormycosis: a study of 43 patients. Egypt J Radiol Nuclear Med. 2018;49(2):447-52.

Cite this article as: Shrestha D, Dev R. Premaxillary and maxillary sinus mucormycosis post COVID: a rare case report. Int J Otorhinolaryngol Head Neck Surg 2021;7:1922-6. 